\title{
Developing and Managing a Community Outreach and Dissemination (COD) Core for a Multi-Institution Grant Project ${ }^{1}$
}

\author{
Angela B. Lindsey, Nadia Bahadori, and Samantha Goldenberg ${ }^{2}$
}

\section{Healthy Gulf, Healthy Communities Project}

The Healthy Gulf, Healthy Communities (HGHC) project, funded by the National Institute of Environmental Health Sciences (NIEHS), works with communities impacted by the 2010 Deepwater Horizon oil spill to conduct research on resiliency and seafood safety. The aftermath of the DWH oil spill prompted a University of Florida (UF)-led team of researchers to study the physiological, psychological, and sociological effects in order to help communities recover and prepare for future potential disasters.

\section{HGHC Series Overview}

The HGHC EDIS Series includes thirteen publications that focus on the work of the community outreach and dissemination team, including community engagement, outreach, and research result dissemination. Community engagement, outreach, and dissemination will serve as the basis for this series of EDIS publications entitled "Healthy Gulf, Healthy Communities Series". Thirteen publications constitute this series with topics focusing on the work of the community outreach and dissemination team. This series can be utilized by Extension faculty and staff for developing and managing outreach cores for large scale grants. This is the third publication in the series and provides additional information about developing a Community Outreach and Dissemination (COD) Core project that include community outreach and engagement.

\section{Introduction}

Chances are, if you have planned a project or program in the past few years, the request for proposals asked about outreach and engagement of community members and/ or target audience. More and more requests for grant proposals, program funding, and funders are asking for an outreach and Extension element of programs and projects. For large grant projects, funders will often ask for proposals to include a Community Outreach and Dissemination (COD) Core. The role of this core is to work closely with researchers and community members to utilize the research to address a need or gap within the community. In addition, the role of this team can be to work with the community to ensure that they are involved in the research process, from research development to research dissemination.

To illustrate how to develop and manage a COD Core in a large grant, this publication will discuss the process with the Healthy Gulf, Healthy Communities Project, which utilized a COD Core. The Core worked with project

1. This document is AEC657, one of a series of the Department of Agricultural Education and Communication, UF/IFAS Extension. Original publication date December 2018. Visit the EDIS website at https://edis.ifas.ufl.edu for the currently supported version of this publication.

2. Angela B. Lindsey, assistant professor, Department of Family, Youth and Community Sciences, UF/IFAS Center for Public Issues in Agriculture and Natural Resources; Nadia Bahadori, alumni, Department of Family, Youth and Community Sciences; and Samantha Goldenberg, graduate student, Department of Family, Youth and Community Sciences; UF/IFAS Extension, Gainesville, FL 32611.

The Institute of Food and Agricultural Sciences (IFAS) is an Equal Opportunity Institution authorized to provide research, educational information and other services only to individuals and institutions that function with non-discrimination with respect to race, creed, color, religion, age, disability, sex, sexual orientation, marital status, national origin, political opinions or affiliations. For more information on obtaining other UF/IFAS Extension publications, contact your county's UF/IFAS Extension office. 
researchers and partnered with Gulf Coast community members to keep them involved in the research projects and to disseminate research findings to meet gaps and needs within communities.

\section{Putting Together a Team}

The significance of the COD Core is that it uses research to identify community level needs in a participatory way that involves citizens in decision making. Furthermore, through expertise and connections of core personnel, it utilizes and expands existing networks and collaborations in the affected communities.

As with any large project, begin with the end in mind and first determine the goals of the COD Core. Once goals are established, identify individuals within your own university, partnering universities, organizations, and individuals in the communities with which you are planning to work. These individuals (in many cases core personnel and research team members) have established connections through current and past work. These connections make great team members and connectors for others in the community to serve on the COD Core. For the Healthy Gulf, Healthy Communities project, the COD Core required a very high level of involvement and commitment from the COD Core team. The team consisted of individuals from two Florida universities, including the University of Florida (UF) and the University of West Florida (UWF), with varying roles. A principal investigator, co-principal investigators, a manager, three faculty members from UF, a coordinator, and two graduate students were involved in the collective efforts. Additional significant contributors included individuals from Florida Sea Grant, UF/IFAS Escambia County Extension Office, UF/IFAS Franklin County Extension office, organizations in the Florida Panhandle, and Florida A\&M University Extension. Representatives from organizations within the region provided network opportunities for the COD Core to identify key community partners.

The development of a grant proposal identified which individuals would carry-out each task. Duties included (1) once-a-month meetings; (2) once-a-quarter face-to-face meetings with UWF representative; (3) identification of community partners; and (4) obtaining letters of support from community members in the proposal.

\section{Multi-Million and Multi-Institution Grant}

Once the COD Core is identified, it is important to align the goals and objectives with the strengths of team mebers. For each goal, determine one or two Core members that would be able to work towards meeting the goal. COD Core members can provide insight on target audiences, including community need and gaps. This information can then be developed into CORE tasks and goals.

The aftermath of the Deepwater Horizon (DWH) oil spill created a critical need to provide information using accessible, actionable channels of communication and education. Community residents needed to understand the research on contamination, potential psychological effects, and community capacity to make informed decisions for themselves and their families.

The goals of the COD Core were focused on the following:

- Identifying resources through research and then matching those critical resources with needs of individuals, families, communities, and small businesses in the Western Florida Panhandle and the Alabama coastline impacted by the DWH disaster;

- Synthesizing the research findings of consortium PIs and translating these through open public channels of communication that foster two-way dialogue and consensus building; and

- Extending the COD Core outreach framework model as a social learning platform designed to mitigate losses and increase resiliency to other disasters, both natural and human initiated.

The core tasks of the COD Core were the following:

- Describe the needs and characteristics of the target population in order to develop best practices and materials for dissemination and promotion;

- Coordinate the translation of relevant information into knowledge suitable to enhancing the preparedness and resiliency of the target population; and

- Strengthen and develop societal structures that empower communities to mitigate losses and increase resiliency to both natural- and human-initiated disasters.

The initial project efforts encompassed existing and longstanding relationships with organizations, state and local agencies, faith-based organizations, and other community 
groups. As partners in the COD Core, individuals from

these agencies and organizations assisted in identifying the

following:

- Resource needs and gaps;

- Participating in year one in a regional forum to share research findings and providing input to developing a strategic plan of action for the outreach core;

- Participating in year four in a regional forum to share research findings and providing strategic direction for work beyond Healthy Gulf, Healthy Communities project;

- Working with COD-Core members to develop input to approaches to materials dissemination and professional training and development;

- Meeting twice a year with COD Core members; and

- Partnering on developing a quick response identification and referral network.

The COD Core expected the following results:

- Research identification and matching needs activities were expected to result in development of effective and culturally relevant strategies and enhanced community resilience;

- Educational programming, training, and advisory committee/community task force/regional forum project infrastructure were expected to develop social capital in the form of new linkages within and between communities and individuals; and

Research that was developed and disseminated because of the project was expected to result in community residents being better able to mitigate their economic loses, improve their health and mental wellbeing, and embark on a process of recovery.

\section{Writing a COD Team into a Grant}

Working with a COD-Core can be a great experience, as it provides a unique partnership between academics and communities. Community COD Core members provide excellent insight into communities including identifying gaps and needs, determining how best to communicate with community members and utilizing research results to help communities. The partnerships developed in COD Cores can result in not only a successful grant, but also greater impacts within communities. 